\title{
Issues on Methods of Identification in Court Ordered Paternity Testing - The Case of Portugal
}

\author{
Helena Machado ${ }^{1 *}$ and Susana Silva ${ }^{2}$
}

${ }^{1}$ Institute for Social Sciences, Department of Sociology, Campus de Gualtar, University of Minho 4710-057 Braga, Portugal

${ }^{2}$ Department of Clinical Epidemiology, Predictive Medicine and Public Health, University of Porto Medical School \& ISPUP - Institute of Public Health, University of

PortoRua das Taipas, $n^{\circ}$ 1354050-600 Porto, Portugal

\begin{abstract}
Official technical and scientific recommendations on standard procedures and quality control in the field of testing of paternity do not cover issues relating to methods of subjects' identification in the processing of paternity investigations that are compulsory for the individuals - parental testing ordered by courts. The aim of this paper is to explore the main issues posed to forensic laboratories when collecting samples for court ordered paternity investigation and therefore contribute to the ongoing debate on social and ethical implications of parental testing and open up new dimensions of this practice. The data was collected from a qualitative study carried out in forensic laboratories in Portugal, based on interviews conducted with forensic experts. The methods for identifying individuals during sample collection are unspecified and heterogeneous and raise several concerns that need to be addressed by common recommendations and an ethically informed code of conduct. Our results indicate that it is needed to start an interdisciplinary discussion about subjects' identification in that context. These practices demand a more effective coordination between courts of law and forensic laboratories and national guidelines for good practices in the case of paternity testing in judicial proceedings.
\end{abstract}

Keywords: DNA fingerprinting, paternity, informed consent, presumed consent, judicial role, records as topi.

\section{Introduction}

Despite some differences in family law systems concerning affiliation laws, most Western European legal systems are historically interconnected and have common legal provisions for the establishment of legal paternity [1], such as the application of the Roman law rule of the presumption of paternity - Pater est quem nuptiae demonstrate which legally ties men to any children born to their wives. Even if there is no biological tie between the child and the mother's husband, the law considers that the husband is the legal father and in most countries it is necessary to take civil proceeding in order to remove that presumption of paternity. As such, marriage retains a privileged place as the preferred way of attributing paternity. In relation to children born outside legal marriage if the unmarried father voluntarily registers the child's birth with the mother, in some countries, such as Portugal, he will automatically be recognised as the legal father. But when that does not occur and the birth certificate does not indicate the identity of the child's father, efforts may be made to establish fatherhood via court proceedings.

DNA testing is currently used to support the legal system's efforts to determine paternity of children born outside legal marriage $[1,2]$. In most European countries the proof of genetic paternity will serve as a basis to establish obligation for the father to financially support the child and he may ask a court order for custody. Some countries in Europe have compulsory inquiries of paternity when the birth certificate of a child does not show the identity of the father (for example, Denmark, Finland, Norway, Sweden, Germany and Portugal). Other countries just give the court the power to investigate paternity in the course of existing civil proceedings regarding the child (for example, Austria, Belgium, France, Greece, Iceland, Italy, Netherlands, Russia, Spain, Switzerland and UK).

The establishment of paternity raises several socio-ethical questions relating to the appropriate use of paternity testing, but the debate have been mainly directed towards the moral, social and policy issues regarding the role and significance of biology and genetics in establishing parental obligations and rights [3-5] and in establishing what constitutes relatedness [2]. Other socio-ethical issues that have been discussed relate to the impact of paternal discrepancy on public health [6] and the implications of misattributed paternity proved by DNA testing [7 8] or genetic mix-ups [9]. There is also a growing body of literature concerning the social impacts of DNA paternity tests on such topics as the media's presentation of this particular biotechnology $[10,11]$, gender differences in attitudes regarding paternity tests [12] or biological kinship [13]. A few studies have also addressed problems related to subjects' identification in parental analysis such as fraudulent substitutions of buccal and blood samples in immigration cases [14-15] and the mixing up of specimen labels of the child and mother within a paternity case [16]. However, to our knowledge, there isn't any research related to the socio-ethical issues that relate to the methods of subjects' identification during the process of sample collection in the context of paternity investigations that are compulsory for the individuals parental testing ordered by courts.

Methods of identification that are used by the forensic laboratories to ascertain the correct identification of donors' samples rais several challenges: the absence of informed consent forms; the communication of information regarding the possible uses either of the identification

*Corresponding author: Helena Machado, Institute for Social Sciences, Departmen of Sociology, Campus de Gualtar, University of Minho 4710-057 Braga , Portugal, Tel: ++351253604212; Fax: ++351253678850; E-mail: hmachado@ics.uminho.pt

Received October 24, 2011; Accepted January 30, 2012; Published February 02, 2012

Citation: Machado H, Silva S (2012) Issues on Methods of Identification in Court Ordered Paternity Testing -The Case of Portugal. J Forensic Res S2:007. doi:10.4172/2157-7145.S2-007

Copyright: @ 2012 Machado $\mathrm{H}$, et al. This is an open-access article distributed under the terms of the Creative Commons Attribution License, which permits unrestricted use, distribution, and reproduction in any medium, provided the original author and source are credited. 
data (photos, fingerprints and personal data) and of genetic information that can be obtained from the biological samples collected for the purposes of determining paternity; and the implications of requesting donors' ethnic group in the set of personal data collected by the laboratory However, until now, the debate about identification issuet in parental testing has been circumscribed within the commercialisation of paternity testing and the possibility of using commercial kits without the knowledge or consent of one of the parties [17] or refusal to consent to the collection of biological samples [18]. In some European countries, consent to be submitted to the collection of a biological sample for the DNA paternity typing is needed (for example, Austria, Belgium, France, Germany, Greece, Iceland, Italy, Netherlands, Russia, Portugal, Spain, Switzerland and UK); while in other countries consent is also generally needed but if the court orders the test, consent is not required anymore (for example, Denmark, Finland, Germany, Iceland, Norway and Sweden).rNevertheless, it should be noticed that even in those countries in which the law indicates that consent is needed even if there is a court order, there are more or less subtle ways to force someone to be submitted to the genetic exam of paternity: refusal without justification may be punished with prison term or payment of fines or can lead to the presumption of paternity, to be evaluated by the court together with other sort of evidence, like the mother, the putative father or witnesses' statements. In France and Italy, for example, refusal to do the paternity test can be freely interpreted by the judge.

Other concerns regarding the appropriate uses of DNA paternity testing have been raised by the Paternity Testing Commission of the International Society for Forensic Genetics, which has published several recommendations on biostatistics [19], laboratory management and quality control [20] for genetic investigations in paternity cases [21]. Such guidelines supplement national and local legislation and laboratory facilities, yet tend to be general in scope and to address only traditional technical and scientific requirements relating to the collection, use and storage of genetic information in paternity cases.

Official technical and scientific recommendations for standard procedures and quality control in the field of paternity genetic testing do not cover issues relating to practices for the identification of individuals in paternity investigation cases ordered by a court of law. The current methods for subjects' identification in paternity cases for collection of personal data are not standardized and there aren't any national or international guidelines on these matters.

Thie fact demands an interdisciplinary discussion that would serve as a foundation to produce general guidelines related to good practices of identificatiot that would serve both the laboratories and the courts requirements. These practices of individuals' identification in genetic paternity testing ordered by courts might have a crosscultural and transnational character, rather than being generated by a configuration of national idiosyncrasies, because the international medico-legal community and, in particular, the European one, seems to characterised by a cultural affinity, even if there are differentiated structural, organisational, functional and operative features [22].

This paper analyses the discourses of forensic scientists working in forensic laboratories located in Portugal concerning methods for identifying individuals during sample collection, and the sort of personal data that is collecte in the specific cases of paternity investigations that are compulsory for the individuals involved - parental testing ordered by courts.

\section{Methods}

A qualitative and interpretative design was used, based on interviews completed between February and May 2010 with six experts who work in laboratories located in Portugal and who have been involved in genetic paternity investigations ordered by courts. In Portugal there are three state laboratories which perform genetic tests at the request of courts of law. The courts can also request universitybased laboratories or private laboratories to carry out DNA paternity testing. The first author contacted all the three state laboratories that exist in Portugal (one declined to participate in the study) and all the forensic laboratories situated in the north region of the country - one university-based and three private laboratories (one private laboratory refused participation). The contact was established by sending a newsletter to the forensic expert responsible for specific paternity testing services in each of the laboratories. Two experts were interviewed in state laboratories, two in one university-based laboratory and two in private laboratories. All the participants had twelve to thirty five years of experience in conducting paternity tests; all of them were the experts responsible for the genetic identification and parentage testing units.

A purposive sampling approach was used, meaning that new data was added to the analysis when it was of theoretical interest and its size was determined by data saturation i.e. recruitment continued until no new themes emerged from the data generated by the interviews.

We followed the Code of Ethics of the International Sociological Association. Semi-structured tape-recorded interviews were administered at the workplace of the experts who volunteered to take part in the study. Oral consent was obtained from the participants for the interviews to be carried out and recorded, after they had been informed of the aim of the study. The participants' anonymity was guaranteed and they were told that they could refuse to answer any question.

The participants were asked to describe their professional experiences and practices in the context of genetic paternity investigations ordered by the courts. For the purposes of this paper we will only considered the information gathered by posing the following questions to the participants: 1 . "Does the laboratory provide any sort of information regarding the method for sample collection?"; 2 . "Are the purposes of the paternity test explained to the individuals?"; 3 . "What are the methods used for subjects' identification? Were these methods recommended by an external entity or the sort of practices to be used to identity subjects were decided internally?"; 4. "Do you use any sort of document for the purposes of collecting information about the individuals and for obtaining consent (information sheet and consent form)."

The data was systematically coded and summarised into main themes. One theme emerging from the data analysis has been selected for the purposes of this paper: personal identification practices involving individuals who give biological samples. The data was analysed by the two authors and whenever conceptual differences emerged, they were given further consideration and settled by additional joint debate, in order to reach a consensus. The findings are reported below with verbatim quotes from interview transcripts that were selected because they are particularly representative of patterns found in the whole data set.

\section{Results}

On the basis of the interviews, one element common to all the 
laboratories involved in this study was found to be the practice of requesting the identity card of the alleged father and the mother, as well as the birth certificate of the child. This demand to show the identity card was seen as the most suitable way of ensuring correct identification, as this is the normal legal method of doing so:

If we are going to compare three individuals from a genetic point of view, with all the consequences this implies, we have to ensure that we are actually testing the right person. And the only way to do that is to use the normal legal methods for identification, such as the identity card. (Interviewee 3)

Only one forensic worker referred to the possibility of not requesting the identity card and also stated that identity cards could be falsely exchanged. The practice by the forensic expert of photographing the applicants allowed for some control over possible obstacles to correct identification procedures:

[I started taking photographs] in cases when people didn't bring their identity cards, so that I didn't have to say to them "Look, go away and come back with it!" (...) if you don't take a photograph, [the expert] is wholly responsible for identification. (...) The photograph is our evidence (...) an identity card doesn't tell you anything because another person could take the true father's identity card. (Interviewee 5)

The laboratories developed other additional techniques for confirming the identity of individuals due to provide samples for DNA paternity typing. These measures are unspecified and heterogeneous: some laboratories demand the co-presence of all the parties, whilst others do not. Some take photographs and/or fingerprints of the individuals involved, but others do not consider this necessary. The procedures seem to be based on local standard practices developed within each laboratory and on personal judgments and normative assessments of what constitutes good practice in the context of paternity genetic testing. These negotiations involve interactions and a set of social processes that do not pose a threat to objectivity or credible scientific practices. Instead they are what constitute objectivity and a reasonable degree of good practice, from the point of view of the forensic workers.

One forensic expert stated that the international rules for the identification of individuals subject to genetic testing do not specify details and it was necessary to decide on the correct procedures:

In international terms, there are no references to fingerprints. It only says that [correct identification] must be ensured, etc. And the simplest way of ensuring this is by taking fingerprints. (Interviewee 1)

Another interviewee stated that on one occasion someone had complained about their fingerprints being taken and the courts had upheld the complaint. This led to the temporary suspension of fingerprinting, but the practice was eventually re-introduced on the basis of an independent decision taken by the laboratory, which considered that the introduction of a database of DNA profiles for the purposes of criminal investigation, created in Portugal in 2008 [23], had popularised and, to a certain extent, legitimised the practice of taking fingerprints in order to identify individuals subject to the collection of biological samples by court order:

[The court] justified this by saying that the presence of the individual and their signature was sufficient to ensure identification. But now with the database [for criminal investigation], (...) we are starting to take fingerprints again. (Interviewee 2).
All the forensic experts interviewed stated that the laboratory where they worked has a sheet on which the personal data of the individual obliged to provide biological samples was entered: in some cases the applicants themselves filled in the personal data, and in other cases this was done by the experts. In both cases the signature of the individual concerned was required. The actual form in which the signature was obtained could differ, ranging from a simple signature on the sheet containing the personal data to the requirement to sign above the blood sample collected in the laboratory. The main concern was to ensure a means of identification that could not lead to any doubts in court, although there were no written rules on how to proceed with a method of identification that would be valid both for the court and the laboratory. As the following interviewee remarked, after describing how he/she takes a copy of the identity card, requests the individual to sign the sheet which contains their personal data and checks the signature, takes a photograph which is then signed by the individual and also asks them to sign the blood sample that is collected for genetic testing "[these practices] are a series of precautions that we take with regard to identification to avoid any future complications" (Interviewee 4).

Some experts took the personal photograph of the mother, the child and/or the alleged father themselves before the samples were collected, but they did not always asked the applicant for their authorisation The most common argument for justifying not asking for permission was that consent was implied, since taking the DNA test was the result of a court order. For example, one interviewee stated that certification of individual identity is essential in paternity testing by court order and this argument justifies the absence of informed consent to take a photograph: 'I always say: 'I have to [take your photograph]'. I don't ask people if I can do it. I really say: 'I have to take a photograph and put it here [on the individual identification sheet]'." (Interviewee 6) The fact that forensic experts were carrying out genetic paternity testing by court order was also used by some interviewees as a reason for justifying the non-existence of written informed consent in some labs which carry out genetic investigations in paternity cases ordered by courts: In these cases [paternity testing ordered by courts], we are acting only as experts. (...) [The mother and the alleged father] do not [sign a written informed consent form]. I have implicit authorisation [from the court of law] and I carry out the [genetic paternity] test in accordance with that. (Interviewee 5)

Some interviewees described the physical co-presence of the mother-child-alleged father trio during the collection of samples as the gold standard for assuring "correct" individual identification: "Preferably, all applicants should be co-present. (...) This is the first step in identification (...) and I think that the court also wants this." (Interviewee 4). However, other interviewees stated that individual identification cannot be based only on the principle of trusting the mother's and alleged father's testimonies of personal identity. One of the participants stated that "The testimony [from the mother or the putative father] is unreliable evidence" (Interviewee 1), and another declared that "I cannot believe it simply because the mother says 'this is the father" (Interviewee 6).

While some laboratories demand that all the parties concerned take the DNA test at the same time and in the same room, some forensic experts questioned the physical co-presence of the mother-childalleged father trio as the "best practice" for collecting samples, since the situation could be "embarrassing" and create certain "tensions" (Interviewee 2). In their opinion the following circumstances justified collecting samples from the mother, child and alleged father at different 
times: an explicit request presented by the mother and/or alleged father to the labs and/or courts not to be co-present at sample collection, if one of the individuals concerned missed their appointment for the test, violent episodes involving the mother and alleged father in the labs, and if the mother or the alleged father was abroad.

All the interviewees stated that they request the "minimum" personal data from the mother and alleged father, namely the same information that appears on the identity card, such as their name, identity card number, place of residence, date of birth, place of birth, and civil status. In some labs, technicians also asked for the following information: profession, ethnic group, and whether it is the first genetic test they have taken in that lab.

In the following interview transcript, one forensic expert explained the practices of collecting irrelevant personal data for individual identification as a sort of legacy from laboratory practices carried out in the past:

Honestly, we collect data that is of no interest, and we don't really know why we do it. (...) However, I do remember that we once did some statistical work with that data in the past. In the past, though, [because] nowadays (...) we have a lot of things to do that are much more important [than statistical work]. (Interviewee 2)

The interviewees also emphasised the difficulties in communicating complex scientific concepts to judicial actors, mothers and alleged fathers, who were mainly concerned with the results of the genetic test. The participants in this study declared that forensic experts usually give "minimum information" about paternity test procedures to the mothers and alleged fathers because they assume that they have been previously informed by the court about the objectives of the test. From the point of view of the experts, if the applicants have any doubts, they should have the initiative to question the forensic experts. In other words, informed consent should be provided by the court order for DNA paternity testing:

I do not think we are responsible for giving information about laboratory procedures or about what we will do [with genetic information]. In fact, the explanation will be too complicated for the majority of our applicants. Thus, if they ask us, we answer; otherwise, we do not talk about it. When they arrive at the lab, we assume that they have already been informed by the court of law. (Interviewee 2)

The interviewees recognized that mothers actively seek more information about test conditions than the alleged fathers, asking specifically about how the sample will be collected from their babies, requesting non-invasive technical procedures and enquiring whether they and the baby can eat before the sample is collected. These "technical" subjects seemed to be related to the mother's concerns for the health and well being of her child and to the fact that the courts of law cannot respond to these concerns.

\section{Conclusion}

The most current methods for identification in court order paternity testing in Portuguese forensic laboratories is making proof of legal identity, by exhibiting the identity card; visual identification (either by taking a photo of the subject or by asking to the other part if he/she confirms identification); collecting fingerprints; and/or asking for the individuals to sign of a document produced by the forensic laboratory. The sort of collection of personal data may also vary - besides the full name, date and local of birth and nationality, some laboratories may also demand information like civil status, profession and ethnic group.
Taking into account that issues of identification are clearly given priority in terms of professional practice, conduct in the sphere of individual identification needs to be harmonized [24], drawing on the law's reliance on science to certify the individual identification [25]. Thus, the established concepts of good practice in paternity genetic investigations ordered by the courts need to be expanded.

In order to provide more comprehensive information on paternity testing ordered by courts [26], it is necessary to develop a better understanding of what counts as scientific work and what counts as legal/juridical work and how the laboratories and courts should link their activities in the case of practices which involve ensuring individual identification [25]. This discussion rests on the views about what is appropriate for the identification goals of law and genetics [2], contributing to create reasonable expectations for the relationship between law and science being done to serve the justice system's demands [25].

When paternity testing is ordered by the courts it does not necessarily mean implicit consent is given by the mother and alleged father. Better communication between judicial actors, the individuals carrying out the tests and the parentage laboratories [27] is desirable and can benefit from the design of specific educational programmes on counselling and from the exchange of experiences in the field [28] organised firstly on a national level and thereafter on a European level and directed towards experts working both in courts of law and in forensic labs.

The introduction of both national and international guidelines and protocols for paternity testing that must be followed by individual experts and institutions [29] should standardise information sheets, as well as the personal information that should be collected for the purposes of paternity testing ordered by courts, taking into account the fact that there is no need to use information about ethnic groups when the aim is to determine the probability of paternity [30]. Moreover, the inclusion of information about an individual's ethnic group will be based on subjective and generalised categories, as such information will either be based on visual judgements by the forensic technician or the donor's self-classification, which may not correspond with the types of classification used in population genetics research. Also, the use of such classifications is not consensual; these labels may vary greatly over space and time and are rarely applied to some groups, even by the individuals themselves, with any consistency [31]. We also recommend a standard structure and essential contents for readable reports destined for paternity test applicants and judicial actors [32]. To deeper protocols established between forensic laboratories and judicial institutions is needed with the objective of standardizing proceedings that respect the quality control of the laboratories, but also care for the legal requirements and the social contexts surrounding paternity testing [22].

In sum, a protocol adapted to ethics and law should be developed in accordance with the following guidelines:

1. Judicial institutions should define the acceptable methods for identification in court order paternity testing to be used by forensic scientists. The visual identification by the other part, with personal interests in DNA paternity testing, should be excluded as a method of identification.

2. Judicial institutions should define the sort of personal data that should be collected by forensic scientists. To collect information about civil status, profession and ethnic group shouldn't be allowed. 
Citation: Machado H, Silva S (2012) Issues on Methods of Identification in Court Ordered Paternity Testing -The Case of Portugal. J Forensic Res S2:007. doi:10.4172/2157-7145.S2-007

Page 5 of 5

3. Parentage laboratories should propose a standardised information sheet to be delivered to the mother and alleged father by the magistrate before ordering paternity testing. This should include information concerning test conditions (e.g. where and how the sample will be collected), anonymization of data, storage and content of biological samples and possible uses of the genetic information.

4. Parentage laboratories should propose a standardized information sheet for judicial institutions, explaining the scientific and technical basis of DNA paternity test, and suggesting the appropriate questions to be made by courts to the labs.

5. Design of specific educational programmes on counseling to forensic scientists, including guidelines for respecting individual rights (i.e. moral and physical integrity, private life, and ownership of genetic information) during the collection of genetic information.

\section{Acknowledgments}

We would like to thank the Foundation for Science and Technology (Portuguese Ministry of Science and Education), the Programme COMPETE and the Commission for Citizenship and Gender Equality for supporting this research, through the project "Mother and fathers after the biological truth? Gender, inequalities and parental roles in the cases of investigation of paternity" (ref. FCOMP-01-0124-FEDER-008483), hosted at The Center for Social Studies, University of Coimbra, Portugal.

\section{References}

1. Forder C, Saarloos K (2007) The establishment of parenthood: a story of successful convergence. In Antokolskaia M (Edn) Convergence and Divergence of Family Law in Europe. Intersentia, Oxford 169-236.

2. Haimes $E$ (2006) Social and ethical issues in the use of familial searching in forensic investigations: insights from family and kinship studies. J Law Med Ethics 34: 263-276

3. Draper H, Ives J (2009) Paternity testing: a poor test of fatherhood. J Soc Welfare Fam Law 31: 407-418.

4. Rothstein MA, Murray TH, Kaebnick GE, Majumder MA (2005) Genetic Ties and the Family - The Impact of Paternity Testing on Parents and Children. The Johns Hopkins University Press, Baltimore.

5. Sheldon S (2009) From "absent objects of blame" to "fathers who want to take responsibility": reforming birth registration law. J Soc Welfare Fam Law 31: 373-389.

6. Bellis MA, Hughes K, Hughes S, Ashton JR (2005) Measuring paternal discrepancy and its public health consequences. J Epidemiol Community Health 59: 749-754.

7. Draper H (2007) Paternity fraud and compensation for misattributed paternity. J Med Ethics 33: 475-480.

8. Turney L, Wood P (2007) "Paternity fraud" and the invisible child. Aust J Emerg Tech Soc 5: 119-131.

9. Murray TH, Kaebnick G (2003) Genetic ties and genetic mixups. J Med Ethics 29: 68-69.

10. Turney L, Gilding M, Critchley C, Shields P, Bakacs L, et al. (2003) DNA paternity testing: public perceptions and the influence of gender. J Emerg Tech Soc 1: 21-37.

11. Turney $L$ (2006) Paternity testing and the biological determination of fatherhood J Fam Stud 12: 73-93.

12. Hayward LS, Rohwer S (2004) Sex difference in attitudes toward paternity testing. Evol Hum Behav 25: 242-248.

This article was originally published in a special issue, Forensic Medicine handled by Editor(s). Dr. Kate Barnes, University of Derby, UK
13. Nash C (2004) Genetic kinship. Cultural Studies 18: 1-33.

14. Wenk RE (2011) Detection of genotype recycling fraud in U.S. immigrants. J Forensic Sci 56: S243-246.

15. Wenk RE (2010) Sporadic genotype recycling fraud in relationship testing of immigrants. Transfusion 50: 1852-1853.

16. Houtz T, Chiafari FA, Wenk RE (2004) Controlling specimen misidentification in parentage analysis. Transfusion 44: 1258-1259.

17. Gilding M (2004) DNA paternity testing without the knowledge or consent of the mother. Family Matters 68: 68-76.

18. Frank R (1996) Compulsory physical examinations for establishing parentage. Int J Law Pol Fam 10: 205-218.

19. Gjertson DW, Brenner CH, Baur MP, Carracedo A, Guidet F, et al. (2007) ISFG: recommendations on biostatistics in paternity testing. Forensic Sci Int Genet 1: 223-231.

20. Morling N, Allen RW, Carracedo A, Geada H, Guidet F et al. (2002) Paternity testing commission of the international society of forensic genetics: recommendations on genetic investigations in paternity cases. Forensic Sc Int 129: 148-157.

21. Schneider PM (2007) Scientific standards for studies in forensic genetics. Forensic Sci Int 165: 238-243.

22. Ferrara SD, Pfeiffer $H$ (2010) Unitariness, evidence and quality in biomedicolegal sciences. Int J Legal Med 124: 343-344.

23. Government of Portugal (2008) Lei n. ${ }^{\circ}$ 5/2008 de 12 de Fevereiro de 2008 [Law no. 5/2008 of 12 February 2008]. Diário da República (I série) 30: 962-968.

24. Francis LP (2010) The physician-patient relationship and a national health information network. J Law Med Ethics 38: 36-49.

25. Jasanoff $S$ (2006) Just evidence: the limits of science in the legal process. $J$ Law Med Ethics 34: 328-341.

26. Mascalzoni D, Janssens AC, Stewart A, Pramstaller P, Gyllensten U et al (2010) Comparison of participant information and informed consent forms of five European studies in genetic isolated populations. Eur J Hum Genet 18 296-302.

27. Wenk RE (2004) Testing for parentage and kinship. Curr Opin Hematol 11: 357-361.

28. Silverman RD (2008) Enhancing public health law communication linkages. $J$ Law Med Ethics 36: 29-49.

29. Troy ESF (1997) The genetic privacy act: an analysis of privacy and research concerns. J Law Med Ethics 25: 256-272, 230.

30. Fernandes AT, Gonçalves R, Brehm A (2004) Databases: the real importance in paternity testing. Progress in Forensic Genetics 10 1261: 463-464.

31. Nuffield Council on Bioethics (2007) The forensic use of bioinformation: ethica issues.

32. Pinto N, Gusmão L, Amorim A (2010) Likelihood ratios in kinship analysis: contrasting kinship classes, not genealogies. Forensic Sci Int Genet 4: 218219. 